\title{
Five-Year Follow-up of an Immediate Implant Placement in the Aesthetic Zone
}

\author{
Dr. Bhageshwar Dhami, ${ }^{1}$ Dr. Priti Shrestha ${ }^{2}$ \\ ${ }^{1}$ Department of Periodontics, Kantipur Dental College, Kathmandu, Nepal; \\ ${ }^{2}$ Department of Periodontics, KIST Medical College, Kathmandu, Nepal.
}

\begin{abstract}
Immediate implants are placed in the site of surgical extraction of the tooth to be replaced. The percentage success of such procedures varies among authors from 94-100\%. Immediate implant placement is most commonly indicated when tooth extraction is done with pathologies not amenable to treatment. The advantages include reduced post-extraction alveolar bone resorption, shortened treatment time, and the avoidance of a second surgical intervention with regard to delayed implantation. This report describes a case of immediate implant placed in a maxillary central incisor followed by evaluation of soft and hard tissue changes occurring during post-operative period with a follow-up at five years.
\end{abstract}

Keywords: Atraumatic extraction; crown; immediate implant placement; osseointegration.

\section{INTRODUCTION}

Immediate implants are defined as the placement of implants in the course of surgical extraction of the teeth to be replaced. ${ }^{1}$ Conventionally, after tooth extraction, the alveolar socket is allowed to heal completely prior to the placement of a dental implant which leads to the prolonged treatment time and bone resorption during the first three months of healing. ${ }^{2}$ In order to avoid the problem of post-extraction and implant-related bone resorption, the concept of immediate implants was introduced in the late 1970s. Clinical evidence demonstrated the role of immediate implants in limiting physiological bone remodelling following tooth extraction. ${ }^{3}$ In contrast to these initial results, numerous other studies published during the last five years report excellent survival rate, degree of osseointegration and maintenance of interdental bone levels with the use of immediate implant protocol. ${ }^{4}$

\section{CASE REPORT}

A 22-year-old male patient with no significant medical history was referred to a private clinic (Om Dental Clinic

\footnotetext{
Correspondence:

Dr. Bhageshwar Dhami

Department of Periodontics, Kantipur Dental College,

Kathmandu, Nepal.

email: dhamibhagesh@gmail.com

\section{Citation}

Dhami B, Shrestha P. Five-Year Follow-up of an Immediate Implant Placement in the Aesthetic Zone. J Nepal Soc Perio Oral Implantol. 2018;2(2):2018;2(2):76-9.
}

and Implant Center, New Baneshwor, Kathmandu) regarding dental implant or needful. Patient presented with a root stump in upper right front region and gave the history of trauma to maxillary right central incisor many years back. The patient had undergone root canal treatment along with a post and crown for the same tooth. Patient complained about the unpleasant look due to the wearing away of the crown (Figure 1, 2, 3).

The treatment modalities were explained to the patient after thoroughly analysing the clinical and radiographical data. An immediate implant-supported prosthesis sounded promising to the patient. Prior to implant surgery, maxillary and mandibular impressions were made to fabricate a maxillary transitional denture which would enhance the healing of extraction sockets as well as the aesthetic appeal of the patient after extraction. Immediate implant surgery was carried out in the following appointment. A full thickness flap was reflected with a No. 15 blade after anaesthetising the area, with an utmost care to preserve the interdental papilla (Figure 3). Atraumatic extraction of the maxillary central incisor was performed using a periotome (Figure 4, 5). An implant depth gauge was used to ensure the intact buccal bone plates and thorough curettage was performed to ensure total debridement of infra bony pocket. The osteotomy site preparation started with a $2 \mathrm{~mm}$ pilot drill into the socket till $13 \mathrm{~mm}$ length. The pilot drill was extended 2-3 $\mathrm{mm}$ in the socket beyond the apex of the extracted teeth. Subsequent drilling along with the copious amount of saline irrigation was carried out to place $4.2 \times 13 \mathrm{~mm}$ (Alpha Bio, Israel) 


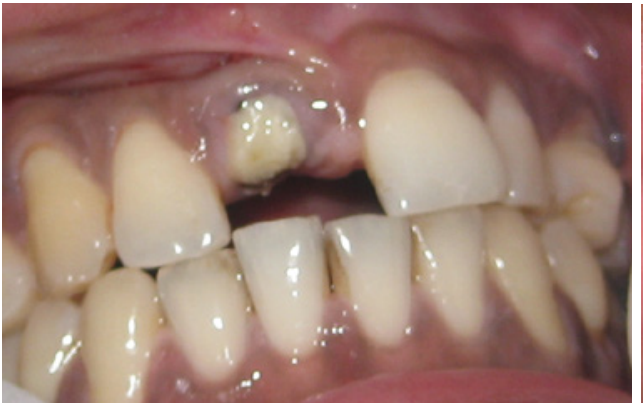

Figure 1: Root stump - central incisor.

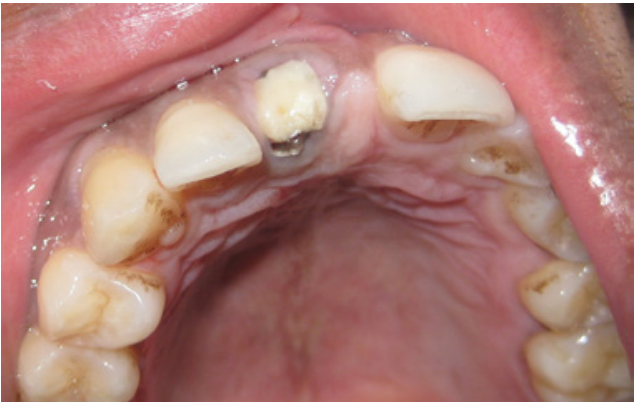

Figure 2: Occlusal view.

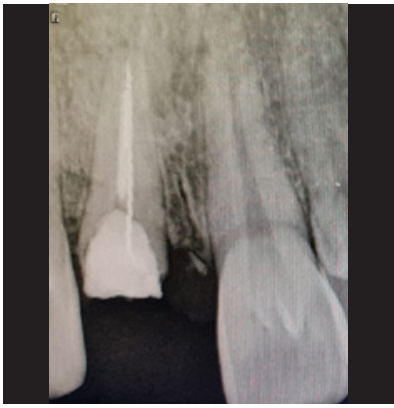

Figure 3: IOPAR showing root stump. within the extracted site (Figure 7). However, an adequate torque could not be achieved to carry out immediate loading, so the sutures were placed with 4-0 silk suture along with a healing abutment (Figure 6).

Post surgical instructions along with antibiotics and analgesics were given to the patient. Chlorhexidine mouthwash was prescribed for two weeks. Sutures were removed after 10 days and an uneventful healing was assessed. A closed tray implant level impression was made after four months. A try-in was carried out for the laboratory fabricated crown in patient's mouth. The occlusion was adjusted and a glazed, porcelain fused to metal (PFM) crown (Figure 8) was cemented with temporary cement. After one month, the crown was permanently cemented using polycarboxylate cement (Prime-Dent Mfg. Inc. Chicago, IL, USA). Proper oral hygiene instructions were given to the patient and reviewed after a month. Oral hygiene instructions were reinforced at the visit. However, patient could not come in-between for Follow-up visits as he was pursuing his studies abroad. At the 5-year follow-up examination, the implant was fully osseointegrated, presenting satisfactory functional and aesthetic conditions without clinical or radiographic signs of alterations or pathologies (Figure 9, 10).

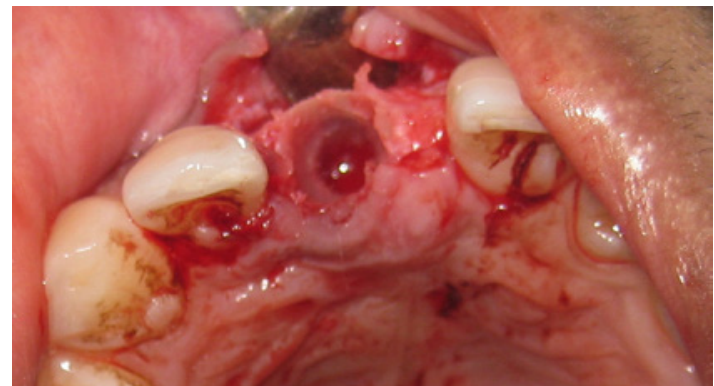

Figure 4: Extraction socket immediately after extraction.

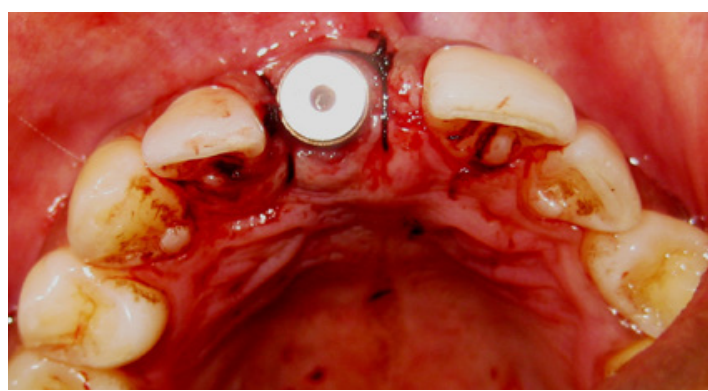

Figure 6: Implant placement with healing abutment.

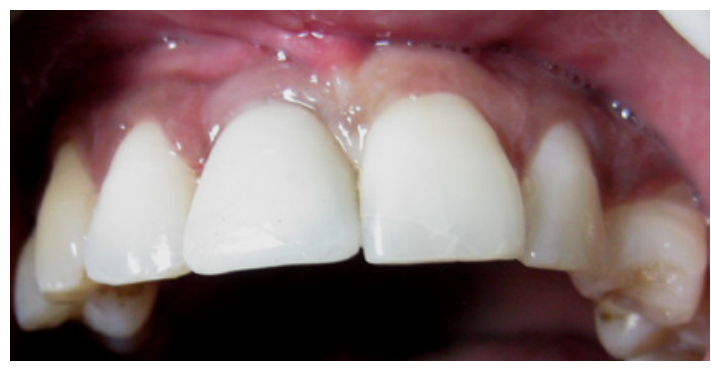

Figure 8a: Final prosthesis with PFM crown.

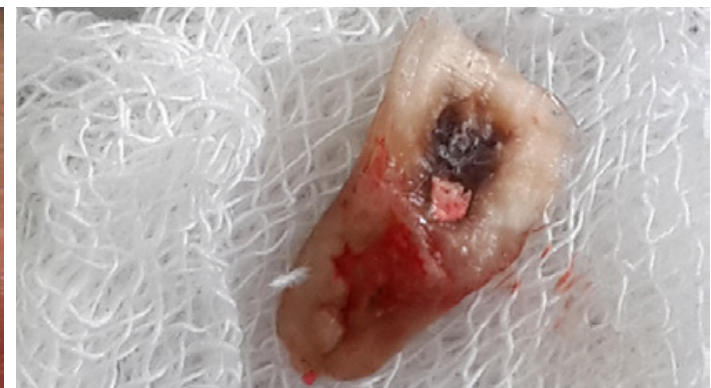

Figure 5: Extracted root.

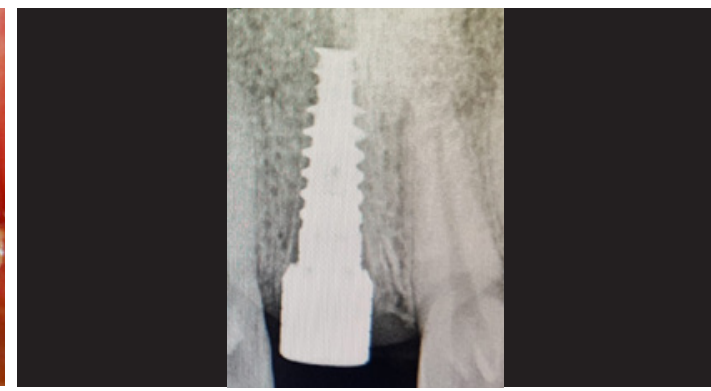

Figure 7: IOPAR showing implant with healing abutment.

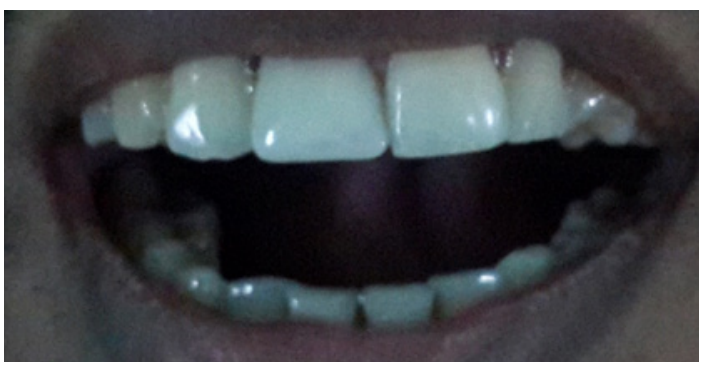

Fig 8b: Final prosthesis with PFM crown. 


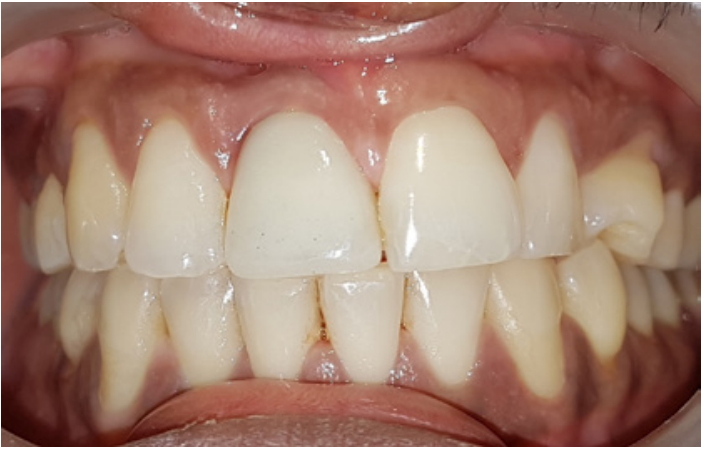

Figure 9: PFM crown with five years Follow-up.

\section{DISCUSSION}

Immediate implant placement is most commonly indicated when tooth extraction is done due to trauma, endodontic causes, root fracture/resorption/perforation, unfavourable crown to root ratio (not due to periodontal loss) and bony walls of alveolus that are still intact. Contraindications include presence of active infection, insufficient bone $(<3$ $\mathrm{mm}$ ) beyond the tooth socket apex for initial implant stability and wide and/or long gingival recession.

Clinical Guidelines for Aesthetic Outcomes When Using Immediate Implant Protocol includes: 1) Thick and intact buccal bone wall, 2) Thick gingival biotype, 3) Minimal trauma in tooth extraction, 4) Presence of at least three socket walls-ideally four walls, 5) Implant shoulder should be placed 2-3 $\mathrm{mm}$ apical to anticipated gingival margin, 6) Primary implant stability with engagement of 3-4 mm bone apical to root apex. 7) Slight palatal/lingual positioning of implant, and 8) Fill the gap between implant and inner bone surface using a low resorbing bone graft material with or without membrane. ${ }^{5}$

Dental implant therapy is the first choice of treatment modality for the replacement of missing teeth. Patients are more satisfied with implant supported prosthesis in terms of comfort, stability and aesthetics compared to conventional prosthesis. ${ }^{6}$ In the present case, implant was successfully osseointegrated with no signs of pain or discomfort and no periapical radiolucency at the end of the five years.

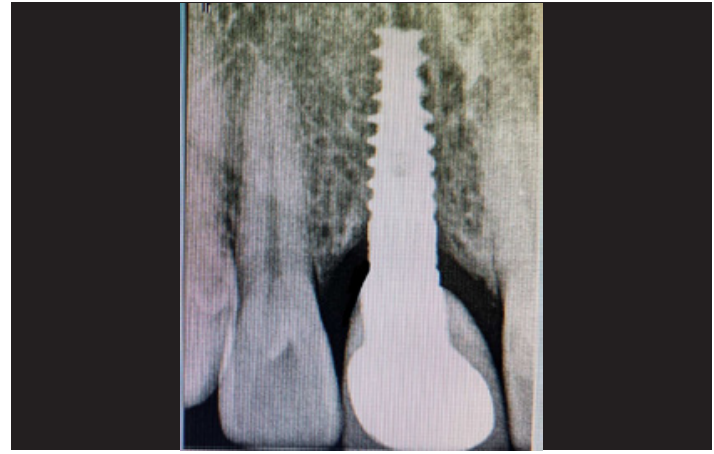

Figure 10: IOPAR showing dental implant with prosthesis after five years.

Many clinical reports and experimental studies have demonstrated favourable outcome of dental implants immediately placed in fresh extraction socket, without the use of any regenerative materials..$^{7-9}$ Clinical and radiographical records of this case show a favourable survival rate of immediate implantation at five years which is comparable to the cases where implants were placed in the healed site. These data agree with those from other authors who evaluated the clinical success rate of immediate implantation without use of any membrane or graft material in both humans and animals. ${ }^{10}$

Single-tooth implants have shown high success rates in both the anterior and the posterior regions of the maxilla and the mandible. ${ }^{11}$ Immediate implant placement has been done since the early years of the clinical application of implants with very good clinical outcomes. ${ }^{12}$

This case report describes an atraumatic tooth extraction, followed by dental implant placement with healing abutment without bone grafts to preserve the buccal plate. The gingival tissue surrounding the implant showed stability with no recession at five years of final crown placement. For considering a primary treatment modality, the implant therapy must fulfill both functional and aesthetic requirements. Immediate placement of endosseous implants into extraction sockets achieved high success rate of between 94-100\%, compared to the delayed placement with reduced process of alveolar bone resorption and treatment time. ${ }^{13}$ 


\section{REFERENCES}

1. Adell R, Eriksson B, Lekholm U, Branemark PI, Jemt T. Long-term follow-up study of osseointegrated implants in the treatment of totally edentulous jaws. Int J Oral Maxillofac Implants. 1990;5:347-59.

2. Schropp L, Wenzel A, Kostopoulos L, Karring T. Bone healing and soft tissue contour changes following single-tooth extraction: A clinical and radiographic 12-month prospective study. Int J Periodontics Restor Dent. 2003;23:313-24.

3. Donati M, Botticelli D, La Scala V, Tomasi C, Berglundh T. Effect of immediate functional loading on osseointegration of implants used for single tooth replacement. A human histological study. Clin Oral Implants Res. 2013;24:738-45.

4. Kim TH, Knezevic A, Jorgensen M, Rich S, Nowzari H. A prospective, 1-year observational study of double-threaded tapered body dental implants with immediate loading. J Prosthet Dent. 2015;114:46-51.

5. Javaid MA, Khurshid Z, Zafar MS, Najeeb S. Immediate Implants: Clinical Guidelines for Esthetic Outcomes. Dent J. 2016;4:21-5.

6. Schwartz-Arad D, Chaushu G. Immediate implant placement. A procedure without incisions. J Periodontol. 1998;69:743-50.

7. Esposito M, Grusovin MG, Worthington H, Coulthard P. Intervention for replacing missing teeth: bone augmentation techniques for dental implant treatment. Cochrane Database Syst Rev. 2008;16(3):CD003607.

8. Esposito M, Hirsch JM, Lekholm U, Thomsen P. Biological factors contributing to failures of osseointegrated oral implants. (II) Etiopathogenesis. Eur J Oral Sci. 1998;106(3):721-64.

9. Schwartz-Arad D, Chaushu G. Placement of implants into fresh extraction sites:4-7 years retrospective evaluation of 95 immediate implants. J Periodontol. 1997; 68:1110-6.

10. Strub JR, Kohal RJ, Klaus G, Ferraresso F. The reimplant system for immediate implant placement. J Esthet Dent. 1997;9:187-96.

11. Wagenberg BD, Ginsburg TR. Immediate implant placement on removal of the natural tooth: retrospective analysis of 1,081 implants. Compend Contin Educ Dent. 2001;22:399-404.

12. Cornelini R, Scarano A, Covani U, Petrone G, Piattelli A. Immediate one-stage postextraction implant: a human clinical and histologic case report. Int J Oral Maxillofac Implants. 2000;15:432-7.

13. Watted N, Trabih K, Nour Q, Azzaldeen A, Muhamad AH. Extraction, immediate implant-a case report. Int J Dent Health Sci. 2014;1(4):430-5. 